\title{
Segundo Viaje a la Barranca de Folantongo
}

\author{
Por el Dr. Ladislao Paray
}

En el año de 1942 del 19 al 22 de noviembre hice mi primer viaje a la interesante Barranca de Tolantongo, en el Estado de Hidalgo. En esa excursión encontré gran cantidad de plantas noco comunes, muchas de ellas endémicas. Una reseña del mencionado viaje apareció en el primer número del Boletín de la Sociedad Botánica de México (Enero de 1944).

En ese primer viaje no pude recoger todas las plantas y mu, chas no pudieron ser clasificadas por falta de flores y frutos. Por eso, desde entonces, decidí visitar ese lugar por segunda vez. Los días $1,2,3$, y 4 de noviembre del año en curso repetí mi viaje a ese maravilloso lugar. En: esta reseña deseo mencionar algunas plantas que colecté.

Tengo que hacer notar que las descripciones de dichas plantas que constan en la obra de Standley (Trees and Shrubs of México) no conctuerdan en todo con las plantas encontradas en la Barranca. Eso tal vez indica que por lo mienos algunas sean especies o va riedades no descritas. También se infiere que pocos o ningunos bo tánicos han hecho viajes en esa Barranca, ya que esa localidad nunca se menciona en los tratados de Botánica, a pesar de que es un lugar bien definido $\mathrm{y}$ de que su nombre ro se confunde con ningún otro.

En primer término mencionaré un arbusto que en mi reseña anterior referí con el nombre de OLIVO. Es un arbusto o árbol hasta de 8 metros de altura, con las hojis semejantes a las del olivo. Esta vez encontré flores y con la ayuda del Dr. F. Miranda, logré clasificarlo como Gochnatia hypoleuca (DC.) A. Gray de la familia Compositae. Standley describe esta especie como arbus to $\mathrm{o}$ arbolito de 2 metros y medio; sin embargo, en la Barranca encontramos algunos ejemplares hasta de 8 metros, con tronco hasta de 30 a $40 \mathrm{~cm}$. de diámetro. Su semejanza con el verdadero 
olivo (Olea europaea L.) es sorprendente que hasta los nativos de la región le dan ese nombre.

Otra sorpresa para nosotros fué el hallazgo de la Choysia ter. nata H. B. K., arbolito muty ornamental y aromático, siendo esta la primera vez que lo encontramos en su habitat natural. Las Choysias cubren las laderas superiores de la Barranca en alturas de 1,500 a 1,700 metros sobre el nivel del mar. Sus hojas son ternadas y brillantes y sus flores may aromáticas y el árbol tiene un porte elegante. Como cosa curiosa mencionaré que vulgarmente se confunde la Choysia ternata con un Pittosporum, que es un ár. bol de ornato en el Bosque de Chapultepec. Hace unos 15 años, cuando la mayor parte de los arbustos y los arboles del Bosque teníar etiquetas con sus nombres comunes y botánicos, varios ejem. plares de Pittosporum tő̆ira estaban etiquetados como Choysia ternata. La / ficiadera Choysia, que es nativa de México, la co nocí por primera vez en esa localidad. Casi junto a esta bella $\mathrm{Ru}$ tácea encontramos otro género de la misma familia muy parecido a la Choysia. Se trata de la Ptelea trifolituta L., comúnmente lla mada "zorrillo". Este arbusto, oriundo del continente Americano tambiér tiene hojas trifoliadas o ternadas y se parece por esto a la Choysia, pero su aroma es más fuerte y hasta desagradable a veces porque recuerda el olor del zorrillo.

Uno de los hallazgos más interesantes fué, sin duda, el de la bellísima Portlandia mexicana Zucc. et. Mart., arbusto sumamente elegante, con hojas brillantes, subcoriáceas y con flores blan cas y olorosas de gran tamaño como de 7 a $10 \mathrm{~cm}$. de largo. Estos arbustos crecen más o menos en los mismos lugares que la Hoverdenia speciosa y se asocia con ésta. Según los tratados de Horticultura la Portlandia no se cultiva, a pesar de que es difícil imaginarse un arbusto más elegante y decorativo. Las flores exha lan un aroma delicioso, sobre todo por la noche, y son tan blancas como las camelias. En general la planta recuerda a la Gardenia y a la Coutarea, que pertenecen a la misma familia de las Rubiár ceas. Se distingtuen claramente dos variedades de Portlandia: una de hojas angostas, de uno a dos $\mathrm{cm}$. de ancho y otra con hojas de 4 a $5 \mathrm{~cm}_{4}$. de ancho. Las flores son idénticas en ambas variedades y úricamente las hojas son diferentes. 
Nos llamó la atención un arbusto con hojas tomentosas, casi completamente blancas. Es un espectáculo curioso el conjunto de estos arbustos cubriendo las escarpadas paredes de la Barranca: se trata del Leucophyllum ambiguum Humb. et. Bonpl. de la familia de las Escrofulariáceas. Las flores son moradas, como de uno a uno y medio $\mathrm{cm}$. de largo. Es un arbusto muy elegante y ornamental sobre todo por sus hojas.

La planta herbácea más común en las barrancas es una Ruellia de flores enormes, como de 8 a $10 \mathrm{~cm}$. de largo, de color azur loso violáceo. Se trata de una especie cercana a la Ruellia hirsutoglandulosa (Oerst) Hemsl. Creo que es una de las Ruellias de flores más grandes, únicamente comparable con las de la Ruellia Bourgaci Hemsl.

Una planta que no había visto durante mi primer viaje es bastante abundante en el fondo de la Barranca. Según la descripción de Standley debe ser la Mascagnia macroptera (Moc. et Sess.) Niedenzu., aunque las sámaras de nuestros ejemplares son más pequeñas.

Para finalizar esta reseña mencionaré una Ipomoea arbores cente con grandes flores blancas que ya había visto en mi viaje anterior. Esta Ipomoea es afine a la $I$. arborescens (Humb. et Borpl.) Don., a la Ipomoea Wolcottiana Rose y a otras, pero difiere en muchos caracteres. Según el Dr. F. Miranda puede tra tarse de una especie no descrita. 